Document downloaded from:

http://hdl.handle.net/10251/140183

This paper must be cited as:

Vega, J.; Andrio, A.; Lemus, A.; Díaz, J.; Del Castillo, L.; Gavara, R.; Compañ Moreno, V. (01-0). Modification of polyetherimide membranes with ZIFs fillers for CO2 separation. Separation and Purification Technology. 212:474-482. https://doi.org/10.1016/j.seppur.2018.11.033

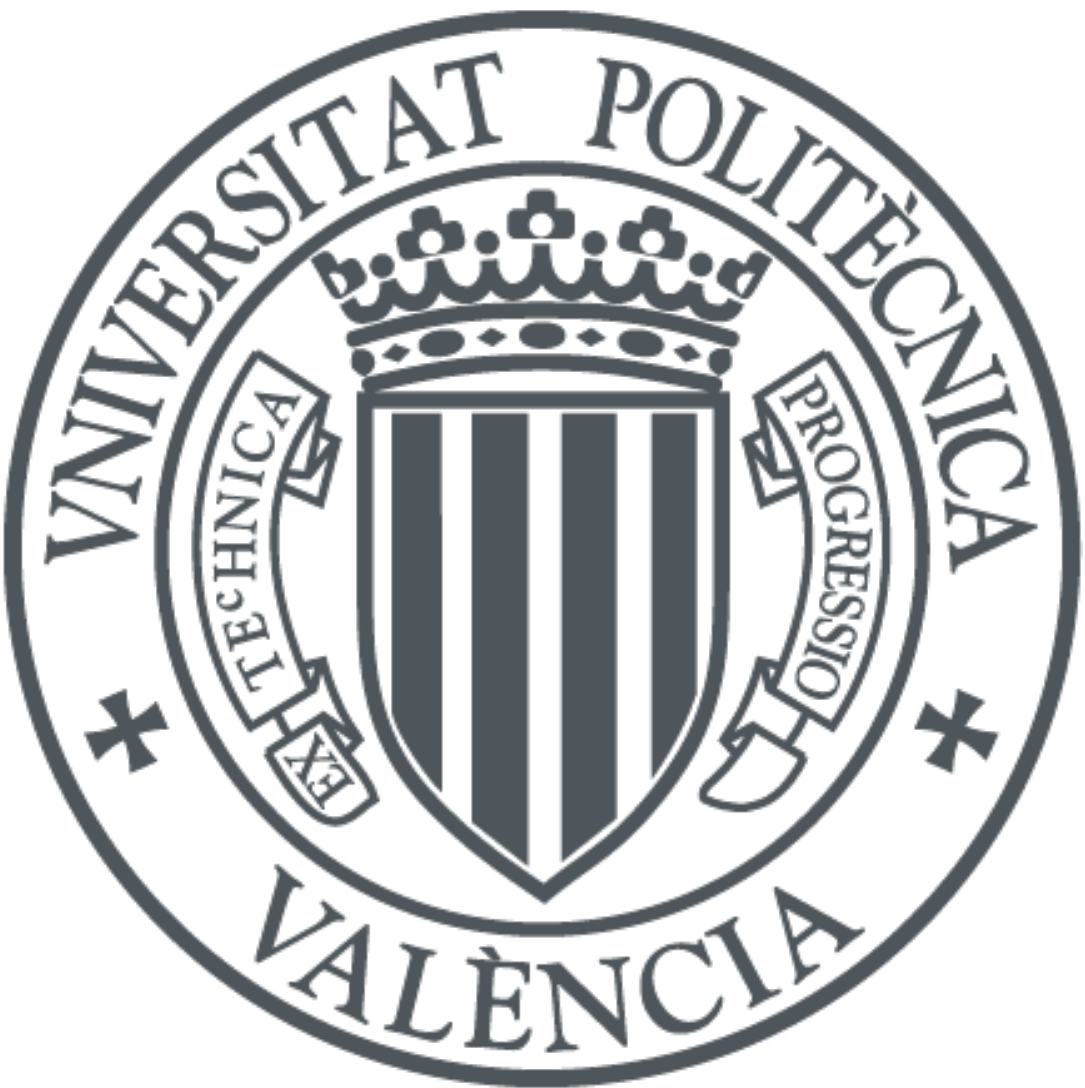

The final publication is available at

https://doi.org/10.1016/j.seppur.2018.11.033

Copyright Elsevier

Additional Information 


\title{
Modification of polyetherimide membranes with ZIFs fillers for $\mathrm{CO}_{2}$ separation
}

\author{
Vega J. ${ }^{1}$, Andrio A. ${ }^{2}$, Lemus A.A. ${ }^{1}$, Díaz J.A.I. ${ }^{1}$, del Castillo L.F. ${ }^{3}$, Gavara R. ${ }^{4}$, ${ }^{*}$ Compañ V. ${ }^{4}$ \\ ${ }^{1}$ Centro de Investigación en Ciencia Aplicada y Tecnología Avanzada, Unidad Legaría, Instituto Politécnico Nacional, CDMX, México. \\ ${ }^{2}$ Departamento de Física, Escuela Superior de Tecnología y Ciencias Experimentales, Universidad Jaime I, 12072 Catellón, Spain. \\ ${ }^{3}$ Departamento de Polímeros, Instituto de Investigaciones en Materiales, Universidad Nacional Autónoma de México (UNAM), Ciudad \\ Universitaria, C. P. 1 70-360, Coyoacán, México DF, 04510 \\ ${ }^{4}$ Food Safety and Preservation Department, IATA-CSIC, Avda. Agustin Escardino 7, 46980 Paterna, Valencia Spain. \\ ${ }^{5}$ Departamento de Termodinámica Aplicada, ETSII, Universidad Politécnica de Valencia, Campus de Vera s/n, 46022 Valencia, Spain.
}

\begin{abstract}
Flat hybrid membranes composed of polyetherimide (PEI) as matrix and zeolitic imidazolate frameworks (ZIFs) as fillers at concentrations of 10 and 20 wt \% were prepared. Apparent permeability coefficient and apparent diffusivity coefficient of gases $\left(\mathrm{CO}_{2}\right.$ and $\left.\mathrm{N}_{2}\right)$ for these hybrid membranes (PZIFs) were determined by the "time-lag" method. The experimental conditions used were from $25{ }^{\circ} \mathrm{C}$ to $55^{\circ} \mathrm{C}$ with pressures of 2,3 and 5 bar. The PZIFs with fillers of ZIF-8 (PZ-Zn) and ZIF-67 (PZ-Co) showed apparent selectivities $\left(\alpha_{P_{a}\left(\mathrm{CO}_{2}\right) / \mathrm{P}_{a}\left(\mathrm{~N}_{2}\right)}\right)$ of 39.6 and 27.5, respectively, higher than the $\alpha_{P_{a}\left(\mathrm{CO}_{2}\right) / P_{a}\left(N_{2}\right)}$ of the reference membrane PEI, while the membrane with filler of ZIF-Mix (PZ-Zn/Co) showed the lowest $\alpha_{P_{a}\left(\mathrm{CO}_{2}\right) / P_{a}\left(\mathrm{~N}_{2}\right)}$ selectivity of 10.3 in the membrane series (under conditions of $25{ }^{\circ} \mathrm{C}$ and 2 bar). It is proposed that the selectivity of the membrane series can be attributed to two critical factors: the particle size/distribution ratio in the polymer base and sorption of $\mathrm{CO}_{2}$ at local sites of the bimetallic mixture.

On the other hand, gas permeation studies $\left(\mathrm{O}_{2}, \mathrm{CO}_{2}\right.$ and $\mathrm{CH}_{4}$, and $\mathrm{CO}_{2} / \mathrm{CH}_{4}$ and $\mathrm{CO}_{2} / \mathrm{C}_{2} \mathrm{H}_{4}$ mixtures), were carried out in the series of PZIFs membranes. Permeability data were obtained by an isostatic method based on a permeation cell connected in series to a gas chromatograph where the rate of permeated gases was analyzed until a stationary state was reached. The complementary characterization techniques were: scanning electron microscopy, thermogravimetric analysis, and powder X-ray diffraction, which support the existence of the amorphous/crystalline phases of the PZIFs.
\end{abstract}

Keywords: Zeolitic Imidazolate Frameworks, Mixed Matrix Membranes, PZIFs, permeability. 


\section{Introduction}

Membrane technology is an attractive and competitive alternative with regard to technologies (for example: separation of gases with amines and reforming of methane with water vapor), which are focused on related processes in obtaining energy and capturing and I or separation of greenhouse gases (especially $\mathrm{CO} 2$ and $\mathrm{CH} 4$ ), which are mostly released into the environment and promote the very well-known global warming. [1] In the last decade, the introduction of polymer membranes in gaseous separation processes, hydrogen recovery $(\mathrm{H} 2 / \mathrm{HC})$, sweetening of natural gas (CO2/ CH4), adjustment of the ratio of synthesis gas or fuel cells ( $\mathrm{H} 2$ / CO2) ), among others, has had an increasing interest due to its multiple benefits, such as: low surface area of operation, assembly of units by modules, low operating costs, the non-use of chemical additives, etc. [2,3] Currently most of the gas separation studies carried out on polymer membranes, [1] asymmetric membranes, [4] and composite membranes, [5] seem to be oriented towards the use of materials such as molecular sieves, where the ratio of pore size / kinetic diameter (polymer / gas, respectively) points to being the predominant factor before the permeation and gas separation. However, another factor that participates in the gas transportation and that has not yet been much studied is the adsorbate-adsorbent sorption process, which can play an important role in the separation of gases in the membrane technology. Today there is a great interest in the research and development of new membrane structures hose objective is to obtain greater selectivity and permeability of specific gases. The polyetherimide (PEI), commercially known as ULTEM $^{\circledR}$, is a high performance thermoplastic polymer with imide, isopropylidene and ether groups [6]. The repeating unit of PEI is $\left[\mathrm{C}_{37} \mathrm{H}_{24} \mathrm{O}_{6} \mathrm{~N}_{2}\right]_{n}$ with molecular weight of $592 \mathrm{~g} / \mathrm{mol}$. The polymer presents glass transition temperature at $215^{\circ} \mathrm{C}$, and decomposition temperature at $427{ }^{\circ} \mathrm{C}$ [6,7]. These features make it interesting for high temperature applications. Zeolitic Imidazolate Frameworks (ZIFs), are members of a new class of organic-inorganic hybrid materials called Metal Organic Frameworks (MOFs), which offer diversity of architectures, pore sizes and high surface areas [8,9]. ZIFs have been used as fillers in polymeric matrices in membrane technology due to its great potential for sorption, separation of mixtures of gases and vapors $[10,11,12,13]$. ZIF-8, which molecular formula is: $\mathrm{Zn}(\mathrm{mIm})_{2}$, (where $\mathrm{mIm}=2$-methylimidazole) has sodalite topology and shows adsorption affinity $\mathrm{CO}_{2}$ molecules; also the ZIF-8 exhibits exceptional thermal and chemical stability 
$[8,14,15]$. ZIF-67, $\mathrm{Co}(\mathrm{mIm})_{2}$, ZIF-Mix, Zn/Co $(\mathrm{mIm})_{2}$, and ZIF-8 are isostructural materials exhibit six members rings $(\sim 3.4 \AA)$ as pore openings $[16,17,18]$. These three materials have shown a differentiated sorption performance (when studied by IGC), due to the charge anisotropy, consequence of the metallic center nature. It seems likely that this behavior would be reproducible employing ZIFs as fillers in the polymeric base PEI.

In the present work, it is proposed that the variation of the permeation coefficients obtained not only depends on the ratio of pore size/kinetic diameter of the gas, but also on the factors such as the isotropy and anisotropy of the electrical charge that are present in each of the ZIFs structures and the dipole moment of the gas in question. So, mixed-matrix flat membranes composed of microporous fillers (ZIF-8, ZIF-67 and the bimetallic mixture ZIF$\mathrm{Zn} / \mathrm{Co}$ ) and the polymeric PEI base were prepared. The pure gas permeation coefficients and gas mixture separation were evaluated for the series of membranes obtained. In addition, the materials obtained were studied by means of DRX, SEM, and TGA to demonstrate the presence of the microporous phase in the polymeric base and to analyze the thermal stability of the obtained membranes.

\section{Experimental}

\subsection{Materials}

Polyetherimide, PEI was purchased from Sabic. N-methyl-2-pyrrolidone ( $\geq 99.7 \%)$, NMP; 2 methylimidazole (99\%), 2-mIm; and zinc chloride ( $\geq 97 \%), \mathrm{ZnCl}_{2}$ were purchased from Sigma Aldrich. Cobalt chloride $(\geq 99.8 \%), \mathrm{CoCl}_{2}$ and sodium formate $(\geq 99 \%), \mathrm{NaCOOH}$ were purchased from Baker Analyzed and Reasol, respectively. Dry $\mathrm{CO}_{2}$ and $\mathrm{CH}_{4}$, and $\mathrm{CO}_{2} / \mathrm{CH}_{4} 50 / 50, \mathrm{CH}_{4} / \mathrm{C}_{2} \mathrm{H}_{4} 50 / 50$ mixtures were supplied by Abello-Linde (Puzol, Spain).

\subsection{Synthesis of ZIF-8}

ZIF-8 (Z-Zn) was synthesized in our laboratory according to the procedure reported elsewhere. [8]. In brief, the mixture of $821 \mathrm{mg}$ of 2-mIm and $765 \mathrm{mg}$ of $\mathrm{NaCOOH}$ in $30 \mathrm{ml}$ of methanol was placed under stirring for $20 \mathrm{~min}$. In a separate beaker a solution of $512 \mathrm{mg}$ of $\mathrm{ZnCl}_{2}$ in $15 \mathrm{ml}$ of methanol was prepared. Both solutions were mixed and stirred for 25 min. Then the resulting mixture was retorted in a PTFE coated stainless steel reactor at 
$130^{\circ} \mathrm{C}$ for $4 \mathrm{~h}$. The final product was centrifuged and the precipitate was washed, centrifuged and dried under vacuum for $12 \mathrm{~h}$.

\subsection{Synthesis of ZIF-67 y ZIF-Mix}

The synthesis of ZIF-67 (Z-Co) and ZIF-Mix (Z-Zn/Co) is similar to that described above: for the synthesis of $\mathrm{Z}$-Co, substituting $483 \mathrm{mg}$ of $\mathrm{CoCl}_{2}$, instead of $\mathrm{ZnCl}_{2}$. In the case of Z$\mathrm{Zn} / \mathrm{Co}$, equimolar amounts of metal ions $(\mathrm{Zn} / \mathrm{Co})$ were used with the aim of promoting a solid solution with metal ratio of $1: 1$.

\subsection{Preparation of colloids and membranes}

PEI:NMP solutions (in 1:3 w/w relation) were mixed to form a solution. Each ZIF was added to the polymer solution at concentrations of $10 \mathrm{wt} \%$ and $20 \mathrm{wt} \%$ of the final solid product (See equation 1). The mixtures were capped and placed in an ultrasonic bath for 2 hour and then stirred during $15 \mathrm{~min}$. After two cycles, membranes were prepared by the casting technique; the colloidal dispersions were spread on a flat glass and placed in an oven where samples were heated from room temperature to $210^{\circ} \mathrm{C}$ (heating rate $=30^{\circ} \mathrm{C} / \mathrm{h}$ ) and kept isothermally for $2 \mathrm{~h}$. The obtained hybrid membranes, PEI/ZIFs or PZIFs, $(100 \pm 18 \mu \mathrm{m}$ thick) were labeled as PZ-Zn (PEI/Z-Zn), PZ-Co (PEI/Z-Co) and PZ-Zn/Co (PEI/Z-(Zn/Co)). The PZIFs membranes and PEI membrane were sealed and stored until further use.

$$
\text { weight } Z I F \%=\frac{\text { weight ZIF }}{\text { weight ZIF + weight PEI }} \times 100 \%
$$

\subsection{X-ray diffraction analysis}

The XRD pattern of the synthesized fillers and membranes were collected using a BrukerAXD D8-Advance diffractometer with Bragg-Brentano theta/theta geometry, with $\mathrm{Cu}$, diffracted beam monochromator and scintillation detector.

\subsection{Porosity analysis}

The $\mathrm{N}_{2}$ adsorption isotherms were recorded at $77 \mathrm{~K}$ with an ASAP 2050 pressure sorption analyzer (from Micrometrics) equipped with a Smart Vac degassing system. The processing of the adsorption data was done to obtain the surface areas (BET) and the volume of 
micropores. The sample was activated under vacuum at $100{ }^{\circ} \mathrm{C}$ for 2 hours before the thermogravimetric analysis

\section{7. Scanning electron microscopy}

The surface morphology of the samples: ZIFs fillers and PZIFs membranes was studied using a field scanning electron microscope (JEOL 7001F EDX-WDX Oxford, INCA 350 / Wave 200). The samples were gold coated and conserved under vacuum before SEM observations.

\subsection{Thermogravimetric analysis}

The thermal stability of the membranes was evaluated with a TGA 2950 thermogravimetric analyzer TA Instruments (New Castle, DE, USA) by heating the sample from $25^{\circ} \mathrm{C}$ until 700 ${ }^{\circ} \mathrm{C}$ at a heating rate of $5^{\circ} \mathrm{C} / \mathrm{min}$. The experiments were carried out under nitrogen atmosphere with $60 \mathrm{ml} / \mathrm{min}$ flux.

\subsection{Apparent permeability of gases}

The gas permeation properties were determined by means of automated gas permeation equipment (see diagram in supporting information) and the variable-volume pressureconstant method [19]. Measuring devices used were: (PFEIFFER) Vacuum pressure sensors with ranges of $1 \times 10^{-3}$ mbar in the lower chamber, 1 bar in the upper chamber and a Dual Gauge ${ }^{\text {TM }}$ transducer (TPG 252-A model). Gas transport gas through dense membranes is usually expressed in terms of the apparent permeability, $\mathrm{P}_{\mathrm{a}}$ and the apparent diffusion coefficient, $\mathrm{D}_{\mathrm{a}}$. The apparent permeability coefficient in the steady-state may be determined by the following expression [20]:

$$
P_{a}=\frac{273}{76} \cdot \frac{\mathrm{V} \cdot \mathrm{L}}{\mathrm{A} \cdot \mathrm{T} \cdot p_{0}} \cdot \frac{d p(t)}{d t}
$$

Where $\mathrm{V}$ is the volume of the lower chamber, $\mathrm{L}$ the thickness of the membrane, $\mathrm{A}$ is the effective area of the membrane interaction, $\mathrm{T}$ the absolute temperature, $\mathrm{p}_{0}$ the pressure of the upper chamber and $\mathrm{dp}(\mathrm{t}) / \mathrm{dt}$ the pressure increase rate in the lower chamber at the steady state. This value is the slope of the line that fits the linear section of pressure vs time plot. The measurement conditions were from $25{ }^{\circ} \mathrm{C}$ to $55{ }^{\circ} \mathrm{C}$ and pressures from 2 bar to 5 bar. 
Apparent diffusion coefficient was obtained using the time lag model, $\theta$, using the expression $[20,21]$ :

$$
D_{a}=\frac{L^{2}}{6 \theta}
$$

The $\theta$ value is obtained as the intersection of the above mentioned line with the time axis. Another important aspect is that gas separation selectivity is considered ideal and defined as $[20,21]$ :

$$
\alpha\left(\frac{A}{B}\right)=\alpha_{A / B}=\frac{P_{A}}{P_{B}}
$$

Where, $\mathrm{P}_{\mathrm{A}}$ and $\mathrm{P}_{\mathrm{B}}$ are the permeation coefficients for gases $\mathrm{A}$ and $\mathrm{B}$, respectively. Frequently the most permeable gas is taken as $\mathrm{A}$, so that $\alpha_{\mathrm{A} / \mathrm{B}}>1$.

\subsection{Permeability to gases}

$\mathrm{O}_{2}$ permeability values were measured in dry conditions by using an Oxtran 2/20 (Mocon, Minneapolis as described earlier [22]. Permeability data for other gases were obtained by an isostatic method based on a permeation cell connected in series to a gas chromatograph (GC) equipped with a TCD detector as described elsewhere [22,23,24]. In brief, the film under analysis separates the two chambers of the permeation cell. In the low concentration chamber, a constant flow of helium $(f)$ carries the permeated molecules out of the cell and to the injection valve of the GC. The high concentration gas on the high concentration chamber a constant flow of the permeant gas (or gas mixture) maintains the pressure of the gas constant at $1 \mathrm{~atm}$ (or $0.5 \mathrm{~atm}$ for gas mixtures). Gas pressures were adjusted by appropriate manometers and flows were controlled by needle valves and measured and mass flow meters from Dakota Instruments (New York). Gas samples of the He flow stream were injected until peak area got constant, indicating the achievement of stationary state. The GC response was previously calibrated by injection of known amounts of the tested gases. Permeability values were calculated from the concentration of the permeant at stationary state $\left(c_{\infty}\right)$ as follows:

$$
P_{i}=\frac{c_{\infty} \cdot L}{f \cdot A \cdot \Delta p_{i}}
$$


Where $\Delta p_{i}$ is the pressure difference of gas " $i$ " between the two chambers of the cell. Experiments were carried out in triplicate. Results shown are the mean values, the experimental error being estimated in $5 \%$.

\section{Results and discussion}

ZIF powders were successfully obtained following the experimental procedure and then incorporated in the polymeric solution to obtain the membranes series PZIFs. PZIFs membranes and the white polyetherimide membrane were studied; although the family of PZIFs membranes starts from the same polymeric base, same synthesis conditions, same concentrations and similar thicknesses $(100 \pm 18 \mu \mathrm{m})$; these membranes only differ in the fillers used: Zn and Co monometallic zeolitic imidazolate frameworks (ZIF-8 and ZIF-67, respectively), in addition to the bimetallic composition $\mathrm{Zn} / \mathrm{Co}(\mathrm{ZIF}-\mathrm{Zn} / \mathrm{Co})$, considered a solid solution. It should be mentioned that the crystalline ZIFs in question are isostructural to each other, so that the pore sizes of the structures are similar among them. [18] Therefore, we proposed that the variation of the permeation coefficients obtained not only depends on the ratio of pore size/kinetic diameter of the gas, but also on the factors such as the isotropy and anisotropy of the electrical charge that are present in each of the ZIFs structures and the dipole moment of the gas in question. It can be said that the network of Z-Zn/Co seen from the atomic level (unlike the Z-Zn and the Z-Co), presents an anisotropic environment of metallic cations Zn and Co, throughout its entire network; The alternating combination of these metals (with ionic radii of $0.074 \mathrm{~nm}$ and $0.063 \mathrm{~nm}$, respectively), promotes the creation of micotensions and local dislocations (between the assembling metal and the binder) that result in an anisotropic behavior of the electric charge which aims to interact with the dipolar and/or quadrupole moment of the gaseous molecules. An example of the above can be seen in the permeation analysis which will be seen in detail later.

\subsection{Porosity analysis}

In the Figure 1. shows the nitrogen sorption isotherms of the Z-Zn, Z-Co and Z-Zn/Co. The results indicate a reversible type I isotherm, characteristic of microporous materials. Porosity analysis of the ZIFs in question by means of isotherms of adsorption/desorption is 
very relevant (especially $\mathrm{Z}-\mathrm{Zn} / \mathrm{Co}$ ), because the $\mathrm{Z}-\mathrm{Zn} / \mathrm{Co}$ to be a solid solution (of the mixture bimetallic $\mathrm{Zn}$ and $\mathrm{Co}$ ) and present an isostructural crystalline structure to that of Z-Zn and Z-Co, showed an intermediate surface area to that of its two predecessors (Z-Zn and Z-Co). The values of BET area and micropore volume are shown in the same figure:

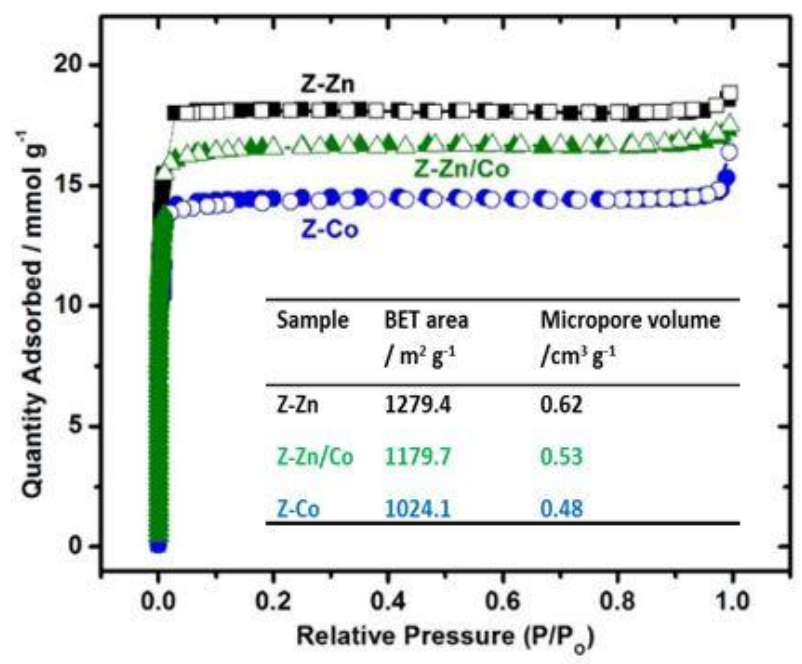

Figure 1. Isotherms of adsorption/desorption of the ZIFs. The closed marks refer to the $\mathrm{N}_{2}$ adsorption measurements while the open marks refer to the desorption measurements.

\subsection{Scanning electron microscopy}

Micrographs of the Z-Zn filler and the PZ-Zn membranes are shown in Figure 2-a and 2-b, respectively. The increase in the concentration of fillers ZIFs in the polymeric base PEI if it affects the strength of the membranes of mixed matrix however it is possible to work without fracture problems using concentrations in $10 w t \%$ and $20 w t \%$. Ma. Josephine and coworkers. [25] report the permeability of $\mathrm{N}_{2}, \mathrm{CH} 4$, and $\mathrm{C}_{3} \mathrm{H}_{8}$ in mixed matrix membranes (composed of matrimid/ZIF-8) in percent weight concentrations of ZIF-8, which they range from $0 \mathrm{wt} \%$ (polymeric base alone) to $60 \mathrm{wt} \%$. The micrographs obtained from the assynthesized Z-Zn powders exhibited well-defined crystallites and an average particle size of $2.6 \mu \mathrm{m}$ (see Figure 2-a), bigger than particle size of the as-synthesized Z-Co and Z-Zn/Co powders $(1.8 \mu \mathrm{m}$ and $1.2 \mu \mathrm{m}$, respectively). On the other hand, a cross-section of the PZ-Zn membrane is shown in Figure 2-b, which exhibits a random dispersion of the particles in the PEI polymer base. Figure 2-c shows in greater detail the fracture and fragmentation of the ZIFs crystalline particles (with an average size has been reduced to $9 \mu \mathrm{m}$ ) located in the 
polymeric matrix. The reduction of the ZIFs particles size and their morphological change of these fillers are associated with the exposure period of the colloidal solution in the ultrasonic bath. This change turned to be advantageous because the crystalline phase is still preserved, while the effective contact area to the permeating gases increases with the increase in the population of small particles well dispersed in the polymer phase.
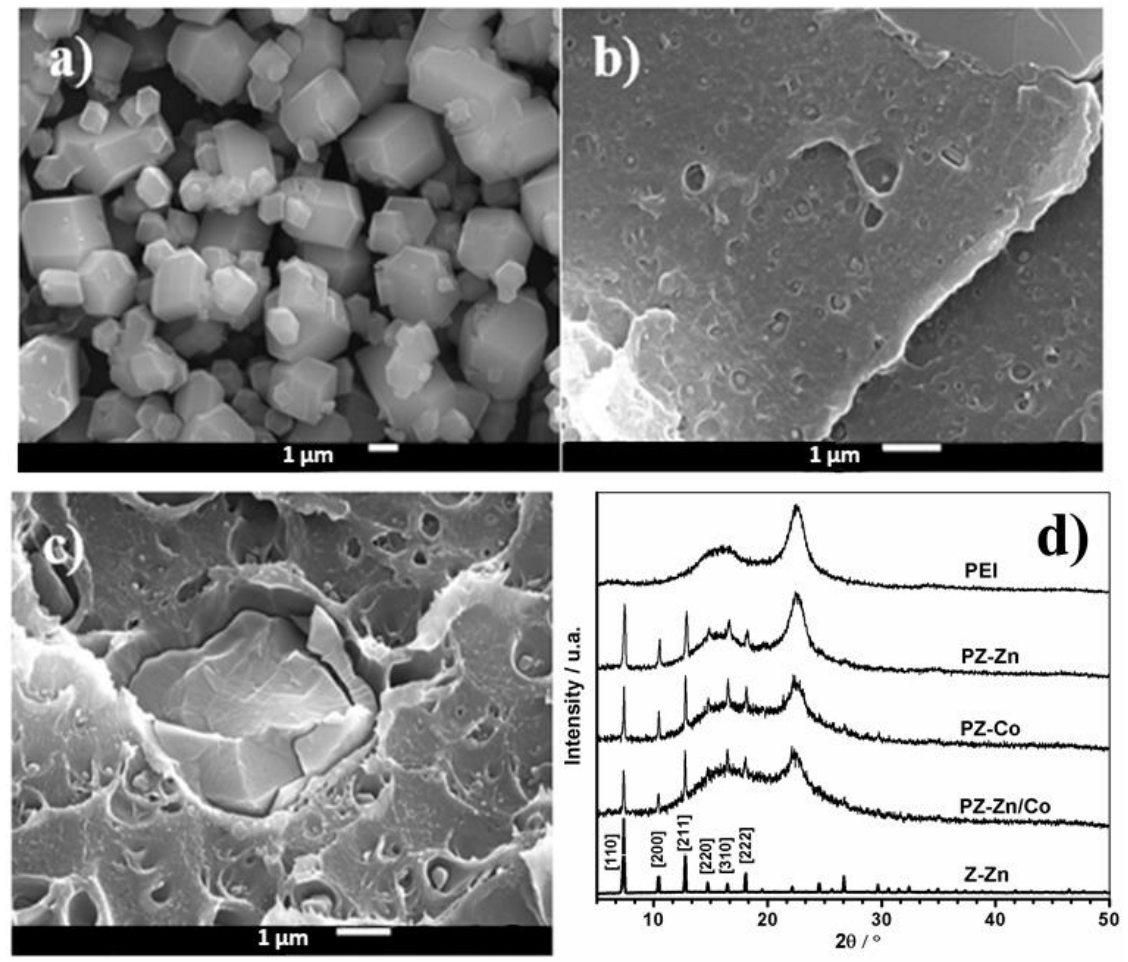

Figure 2. SEM micrographs and XRD patterns. a) Z-Zn, b) PZ-Zn/Co, c) Z-Zn/Co particles fractured inside of PEI and d) $\mathrm{XRD}$ patterns of membrane series and Z-Zn powder.

\subsection{X-ray diffraction analysis}

XRD patterns of the series of membranes and the phase of Z-Zn are shown in Figure 2-d and evidence the presence crystalline of the Z-Zn, Z-Co, and Z-Zn/Co incorporated into the PEI polymer base $[8,26,17]$. The crystalline phases of the obtained ZIF materials were identified using the "Match" program and using the Scherrer equation, the particle size was determined, which has the following trends: Z-Zn $(1225 \AA)>$ Z-Co $(1120 \AA)>$ Z-Zn/Co (879 ̊). In the process of synthesis and self-assembly of the $\mathrm{Z}-\mathrm{Zn} / \mathrm{Co}$, the tensions due to the mixture of metals $(\mathrm{Zn} / \mathrm{Co})$ and the organic linker may be a limiting factor for particle growth. [27] 
Preliminarily in Figure 2-d it can be seen that the first diffraction maximums of the MMM (corresponding to the crystalline phase) are widened compared to the diffraction maximums of the $\mathrm{Z}-\mathrm{Zn}$ sample; This behavior is attributed to finite dimensions of the crystallites, that is, the smaller the crystal, the more atoms will be out of optical coherence and consequently the diffraction maximums will widen. Subsequently, the particle size of the ZIFs fillers within the polymer matrix was determined resulting in smaller crystallites compared to the crystallites before the preparation of the colloid; The results obtained show the following trend: Z-Zn (966 ̊) > Z-Co (941 ̊) > Z-Zn/Co (796 ̊).

\subsection{Thermogravimetric analysis}

The termogravimetric curves of the PZIFs membranes are showed in the Figure 3 . The curves presented a weight loss in the temperature range of $170{ }^{\circ} \mathrm{C}$ to $300{ }^{\circ} \mathrm{C}$, later showed a constant weight profile up to $300^{\circ} \mathrm{C}$. This first weight loss was related to the evaporation of the solvent molecules trapped in the membranes (mainly in the polymeric matrix) and results in 5.4\%, 6\%, 7.2\% and 8\% losses for PEI, PZ-Zn, PZ-Co and PZ-Zn/Co, respectively. It is common to think that the solvent molecules trapped in the membranes could plasticized the matrix increasing the transport of gases and affecting the values of their representative coefficients $\left(\mathrm{P}_{\mathrm{a}}\right.$ and $\left.\mathrm{D}_{\mathrm{a}}\right)$ of the ternary system (polymer/ZIFs/solvent), although this is not our case. Using the PEI membrane as a reference, the permeability values obtained (which will be discussed later) were similar to those reported in the literature. Probably, the solvent molecules were removed during the activation time of the membranes (vacuum of 8 hours) to which they were submitted before each test. As Figure 3 shows, the weight of all PZIFs remained constant within the $300{ }^{\circ} \mathrm{C}-360^{\circ} \mathrm{C}$ range. At $360^{\circ} \mathrm{C}$, the thermograms showed the initiation of a second weight loss which finished ca. $500^{\circ} \mathrm{C}$, and that accounts for ca. $30 \%$ of the original sample weight. This loss could be related with the decomposition of the ZIFs materials. At higher temperatures, the curves showed a similar profile with a smooth slope which is related with the decomposition of the polymer. 


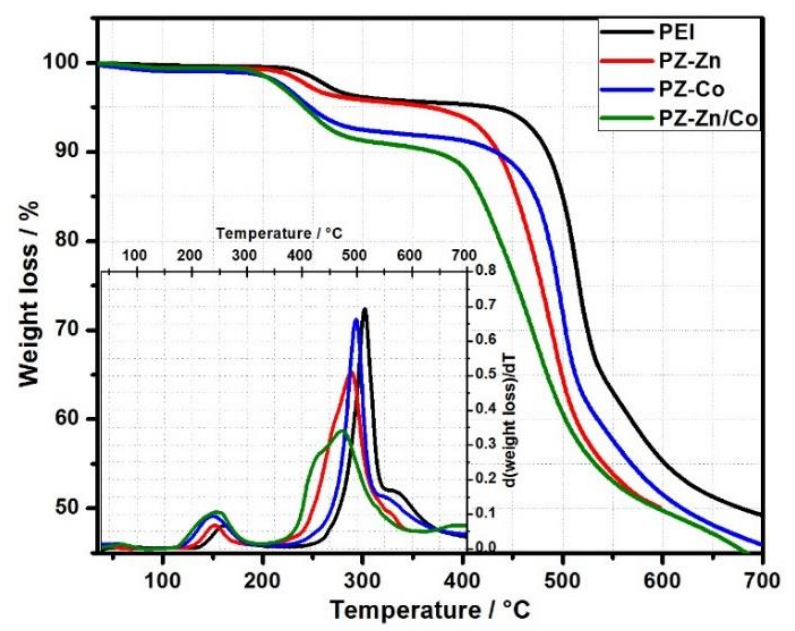

Figure 3. Thermogravimetric analysis of PEI and PZIFs membranes

\subsection{Apparent gas permeation in PZIFs membranes}

Figure 4 shows the permeability coefficients to $\mathrm{CO}_{2}$ and $\mathrm{N}_{2}$ for PEI and PZIFs at $35^{\circ} \mathrm{C}$ and 2 bar conditions. To verify the correct operation and calibration of the permeation equipment, the PEI membrane was taken as a reference. The apparent permeability to $\mathrm{CO}_{2}$ and selectivity of gases $\left(\mathrm{CO}_{2}\right.$ and $\left.\mathrm{N}_{2}\right)$ in the PEI membrane, were $\mathrm{P}_{\mathrm{a}}=1.25$ barrer and $\alpha_{\mathrm{Pa}_{a}\left(\mathrm{CO}_{2}\right) / \mathrm{Pa}_{a}\left(\mathrm{~N}_{2}\right)}=24.01$, respectively, similar to already reported data [28]. In the case of PZIFs membranes at $10 \mathrm{wt}$ $\%$ concentration, the permeabilities were slightly lower than those obtained for the PEI membrane.

On the other hand, the series of membranes of greater concentration (20 wt \%) showed different behaviors: The permeability coefficients for $\mathrm{CO}_{2}$ obtained for the membrane series showed the following trend: $\mathrm{PZ}-\mathrm{Co}>\mathrm{PZ}-\mathrm{Zn}>\mathrm{PEI}>\mathrm{PZ}-\mathrm{Zn} / \mathrm{Co}$; while the permeability coefficients for $\mathrm{N}_{2}$ showed the following trend: $\mathrm{PZ}-\mathrm{Co}>\mathrm{PZ}-\mathrm{Zn} / \mathrm{Co}>\mathrm{PEI}>\mathrm{PZ}-\mathrm{Zn}$. Although the fillers are at the same concentration, isostructural and with similar pore size (3.4 $\AA$ ), the $\mathrm{Pa}_{\mathrm{a}}$ to $\mathrm{CO}_{2}$ for the membrane with PZ-Zn/Co filler was considerably lower. Similar behavior was observed for the rest of temperatures analyzed (see supporting information). This phenomenon could be attributed to intrinsic properties of the filler $\mathrm{Z}-\mathrm{Zn} / \mathrm{Co}$ (since the method of preparation and measurement conditions of the membrane series were the same). Such intrinsic properties should be reviewed in terms of isostructurality, pore size, crystallite size and local charge anisotropy. 


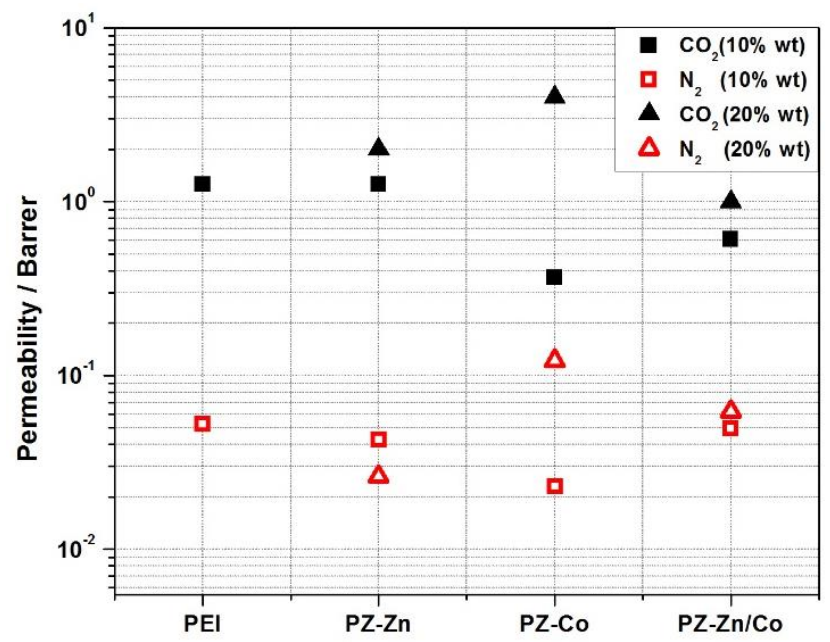

Figure 4. Graphics of permeability series membranes to 2 bar and $35^{\circ} \mathrm{C}$

According to the results observed in the figure 4, it can be considered that the increase of the concentration of the fillers in the PEI polymer base has as consequence the increase of the permeability of the gases through the mixed matrix membrane (MMM), this is attributed to the increase of the contact surface crystallite-polymer. The crystallite-polymer interface present in the MMM can be considered as a number of preferential paths for the transport of gases. Therefore it could be said that, the higher the concentration of the filling, the greater the gas permeability, through these preferential roads; An important fact is that ZIFs are also known for their properties in gas sorption [29,30,31] so having a certain crystallite-polymer contact surface can reduce the permeability of gases and even more when the material counts with seductive properties (such as the anisotropy of electric charge that is present in the Z$\mathrm{Zn} / \mathrm{Co}$ material) that allow it to attract gaseous molecules. In addition, the particle size aims to be another critical factor that participates in the reduction of permeability to $\mathrm{CO}_{2}$ in the membrane with PZ-Zn/Co filler. This filler has smaller crystallite sizes than Z-Zn and Z-Co providing greater effective contact area with the permeant gas. Electron density distribution is not-uniform due to the presence of the metallic cations (local charge anisotropy) and this leads to crystallites with more reduced dimension than in the monometallic ZIFs (Z-Zn and Z-Co). Smaller crystallites better dispersed in the polymer matrix result in larger interacting area for the permeant molecules. Subsequently, the $\mathrm{P}_{\mathrm{a}}$ value decreased by half in the case PZ$\mathrm{Zn} / \mathrm{Co}$ while the $\mathrm{P}_{\mathrm{a}}$ values for the other two ZIFs increased, what it is attributed to the absence of local charge anisotropy, bigger particle size (smaller contact area) and a slight increase in 
pore size. The most important of the three factors is the local charge anisotropy since $\mathrm{CO}_{2}$ molecules have a quadrupole moment of $\left(-4.3 \mathrm{erg}^{1 / 2} \mathrm{~cm}^{5 / 2} \times 10^{26}\right)$ and a polarizability $\left(2.9 \times 10^{-}\right.$ ${ }^{24} \mathrm{~cm}^{3}$ ) that results in an effect on its permeability as a consequence of the contacting area composition [18].

The values of $\mathrm{P}_{\mathrm{a}}$ and $\mathrm{D}_{\mathrm{a}}$ for the developed membranes (obtained by "time-lag" method and with a measurement error of $3 \%$ ) are shown in Table 1 . As it is known, the rapidity at which the mass transport of gaseous molecules occurs across a membrane depends mainly on the size of the kinetic diameter of the permeant gas, so it is usual for the permeation values to be higher for molecules with smaller kinetic diameter and smaller for those with greater kinetic diameter (for example: $P_{\mathrm{CO}_{2}}>P_{\mathrm{N}_{2}}$ ) [20]. The attractive interactions between molecules with quadrupole moment, $\mathrm{Q}$, (such as $\mathrm{Q}_{\mathrm{N} 2}\left(-1.5 \mathrm{erg}^{1 / 2} \mathrm{~cm}^{5 / 2} \times 10^{26}\right)$ and $\mathrm{Q}_{\mathrm{CO} 2}\left(-4.3 \mathrm{erg}^{1 / 2} \mathrm{~cm}^{5 / 2}\right.$ $\left.\times 10^{26}\right)$ ), and the local electric field present in lattices ZIFs, are an example of the sorption force $[18,32]$. In the process of gas transport through the PZIFs, these sorption forces are present and are evidenced on the permeability values obtained (see Table 1).

Table 1

Values of apparent permeability and diffusion coefficients at $35^{\circ} \mathrm{C}$ and $\mathrm{p}_{0}=2$ bars.

\begin{tabular}{lllll}
\hline Membrane & \multicolumn{2}{l}{$\mathbf{P}_{\mathbf{a}} /$ Barrer } & \multicolumn{2}{l}{$\mathbf{D}_{\mathbf{a}} \mathbf{~ 1 0} \mathbf{1 0}^{-10} / \mathbf{c m}^{2} \mathbf{s}^{\mathbf{1}}$} \\
\cline { 2 - 5 } & $\mathrm{CO}_{2}$ & $\mathrm{~N}_{2}$ & $\mathrm{CO}_{2}$ & $\mathrm{~N}_{2}$ \\
\hline PEI & $1.25 \pm 0.08$ & $0.052 \pm 0.002$ & $25 \pm 2$ & $25 \pm 2$ \\
PZ-Zn & $1.79 \pm 0.09$ & $0.031 \pm 0.001$ & $44 \pm 3$ & $30 \pm 3$ \\
PZ-Zn/Co & $0.64 \pm 0.03$ & $0.062 \pm 0.003$ & $106 \pm 5$ & $122 \pm 9$ \\
PZ-Co & $3.33 \pm 0.17$ & $0.120 \pm 0.006$ & $35 \pm 2$ & $20.3 \pm 1.7$ \\
\hline
\end{tabular}

Apparent selectivities, $\alpha_{P_{a}\left(\mathrm{CO}_{2}\right) / P_{a}\left(N_{2}\right)}$, in the series of membranes are shown in Figure 5. The results obtained in the PZ-Zn hybrid membrane with $10 \%$ filler showed a slight improvement in the $\alpha_{P_{a}\left(\mathrm{CO}_{2}\right) / P_{a}\left(N_{2}\right)}$ compared to the control PEI membrane, while that the PZ-Co and PZ$\mathrm{Zn} / \mathrm{Co}$ membranes with $10 \mathrm{wt} \%$ filler showed $\alpha_{P_{a}\left(\mathrm{CO}_{2}\right) / P_{a}\left(N_{2}\right)}$ lower than PEI. The $\alpha_{P_{a}\left(\mathrm{CO}_{2}\right) / P_{a}\left(N_{2}\right)}$ for the PZ-Zn and PZ-Co membranes in concentration $20 \mathrm{wt} \%$ of filler, showed greater selectivity than the PEI, while the PZ-Zn/Co membrane did not show a relevant change. It can be considered that the low $\alpha_{P_{a}\left(\mathrm{CO}_{2}\right) / P_{a}\left(N_{2}\right)}$ of the PZ-Zn/Co membrane is mainly related to the retention of $\mathrm{CO}_{2}$ due to the anisotropy of local charge present in the 
filling, so it can be proposed that the permeability of $\mathrm{CO}_{2}$ in the membrane $(\mathrm{PZ}-\mathrm{Zn} / \mathrm{Co})$ is reduced by effects of a local field and the transport of $\mathrm{N}_{2}$ by the pore size of the membrane. The series of membranes showed a similar behavior at all tested temperature and pressure conditions (see complementary material). Table 2 shows effect of temperature on the apparent permselectivity values obtained for the PZIFs membranes at 2 bar pressure.
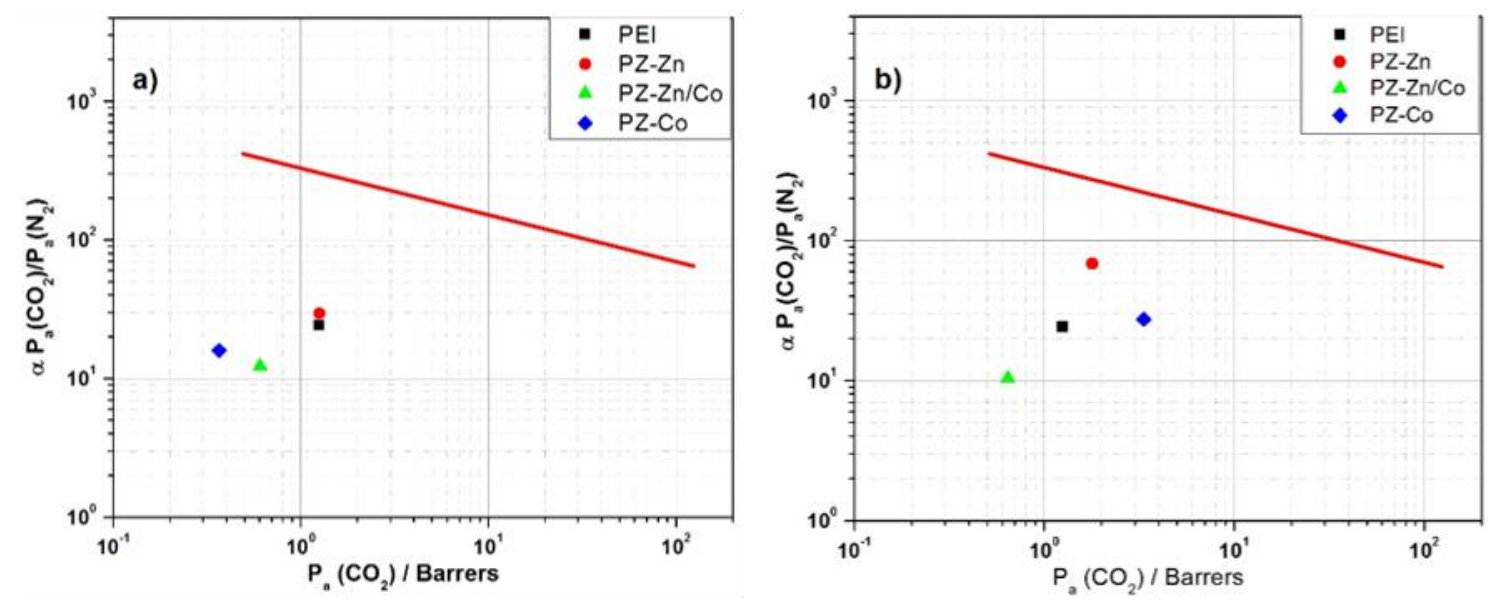

Figure 5. Apparent selectivity in PZIFs and PEI at $2 \mathrm{bar}$ and $35^{\circ} \mathrm{C}$ : PZIFs with a) $10 \mathrm{wt} \%$ fillers and b) 20 wt $\%$ fillers

Table 2. Apparent selectivities to membrane white $20 \%$ wt at 2 bar.

\begin{tabular}{lllll}
\hline \multicolumn{5}{c}{$\alpha_{P_{a}\left(\mathrm{CO}_{2}\right) / P_{a}\left(\mathrm{~N}_{2}\right)}$} \\
\hline \multirow{2}{*}{$\mathrm{T} /{ }^{\circ} \mathrm{C}$} & \multicolumn{4}{c}{ Sample } \\
\cline { 2 - 5 } & PEI & PZ-Zn & PZ-Zn/Co & PZ-Co \\
\hline 25 & $20.38 \pm 0.02$ & $46.81 \pm 0.05$ & $5.11 \pm 0.01$ & $30.53 \pm 0.07$ \\
35 & $24.01 \pm 0.04$ & $39.60 \pm 0.05$ & $10.35 \pm 0.02$ & $27.35 \pm 0.09$ \\
45 & $24.90 \pm 0.04$ & $35.49 \pm 0.06$ & $11.62 \pm 0.03$ & $22.94 \pm 0.10$ \\
55 & $26.48 \pm 0.05$ & $33.82 \pm 0.07$ & $13.13 \pm 0.04$ & $22.42 \pm 0.10$ \\
\hline
\end{tabular}

Samano and coworkers. [18] reported the separation of the $\mathrm{H}_{2} / \mathrm{CO}_{2}$ and $\mathrm{CH}_{4} / \mathrm{CO}_{2}$ binary mixtures using packed columns of ZIFs (ZIF-4, ZIF-8, ZIF-67 and ZIF-ZnCo). The gas separation study showed that the solid ZIF-Zn/Co solution exhibited higher sorption of molecules with quadrupole moment (for example $\mathrm{H}_{2}$ and $\mathrm{CO}_{2}$ ) compared to their analogues. The chromatographic profile of Figure 6 shows the response times of the $\mathrm{CH}_{4} / \mathrm{CO}_{2}$ binary mixture using a column packed with $\mathrm{PZ}-\mathrm{Zn} / \mathrm{Co}$ fillers at a concentration of $10 \mathrm{wt} \%$ and a temperature at $30{ }^{\circ} \mathrm{C}$; the results of this study showed shorter response times compared to those obtained in a column packed with ZIF-ZnCo powders (5 times smaller) previously 
reported [13]. The separation behavior for the gas mixture $\mathrm{CH}_{4} / \mathrm{CO}_{2}$ in the column with PZ$\mathrm{Zn} / \mathrm{Co}$ gaskets (similar to the behavior of $\mathrm{ZIF}-\mathrm{ZnCo}$ ) supports the hypothesis of $\mathrm{CO}_{2}$ sorption in local sites of the PZ-Zn/Co membrane, explaining the reduction of selectivity when using gases with relatively large kinetic diameters and molecules with quadrupole moments.

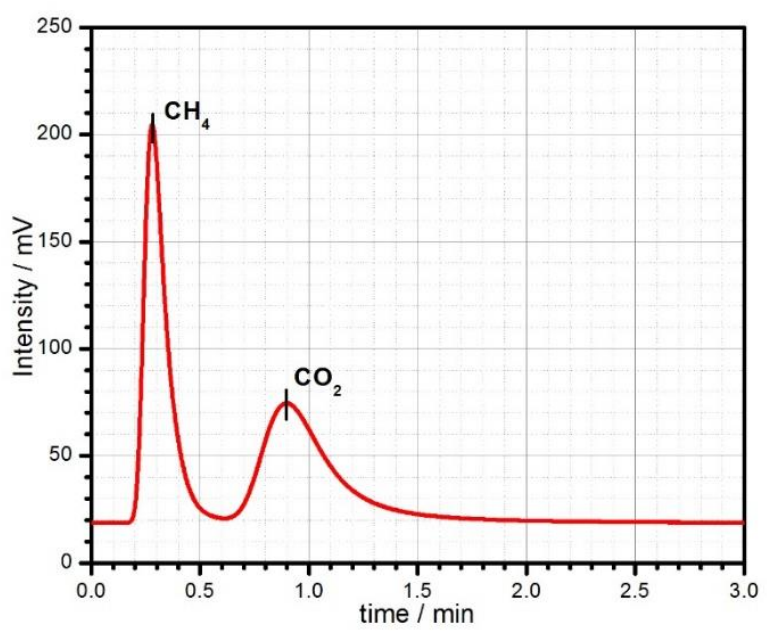

Figure 6. Chromatogram of separation $\mathrm{CH}_{4} / \mathrm{CO}_{2}$ in $\mathrm{PZ}-\mathrm{Zn} / \mathrm{Co}$

Assuming that the gas transport processes through these membranes are thermally activated, the activation energy values can be calculated using the Arrhenius equation:

$$
\mathrm{X}=X_{0} \exp \left(\frac{-E_{X}}{R T}\right) \quad E q .6
$$

where $X$ stands for apparent of permeation or diffusion coefficient $\left(\mathrm{P}_{\mathrm{a}}\right.$ and $\left.\mathrm{D}_{\mathrm{a}}\right), X_{0}$ corresponds to the pre-exponential factor and $E_{\mathrm{x}}$ to the activation energy of $\mathrm{P}_{\mathrm{a}}$ or $\mathrm{D}_{\mathrm{a}}$. Arrhenius plots of $\mathrm{P}_{\mathrm{a}}$ and $\mathrm{D}_{\mathrm{a}}$ to $\mathrm{CO}_{2}$ and $\mathrm{N}_{2}$ for the PEI and PZIFs membranes at 2 bars are shown in Figure 7 and the calculated activation energy values are included in Table 3. The activation energies associated with $\mathrm{CO}_{2}$ permeation coefficients in the membranes decreased in the order: PZ-Zn/Co> PEI> PZ-Zn> PZ-Co, at 2 bars. The activation energies for $\mathrm{N}_{2}$ in the series of membranes showed less variation compared to $\mathrm{CO}_{2}$, although the values obtained can also be ordered as: PZ-Zn > PZ-Zn/Co > PEI > PZ-Co in the third column of Table 3. The values of the apparent sorption enthalpies of $\mathrm{CO}_{2}$ and $\mathrm{N}_{2},\left(\Delta H_{\mathrm{S}}=\mathrm{E}_{\mathrm{P}}-\mathrm{E}_{\mathrm{D}}\right)$, are also shown in Table 3. It is noticeable that the sorption enthalpy values calculated for the PZIFs are of the same order than those obtained for the fillings in their single phase [18]. These values indicate that the solubility processes of $\mathrm{CO}_{2}$ in PEI membrane and hibrid 
membranes with fillers Z-Zn and Z-Co are exothermic. On the contrary, for membranes with $\mathrm{Z}-\mathrm{Zn} / \mathrm{Co}$ the sorption processes for $\mathrm{CO}_{2}$ and $\mathrm{N}_{2}$ are endothermic.
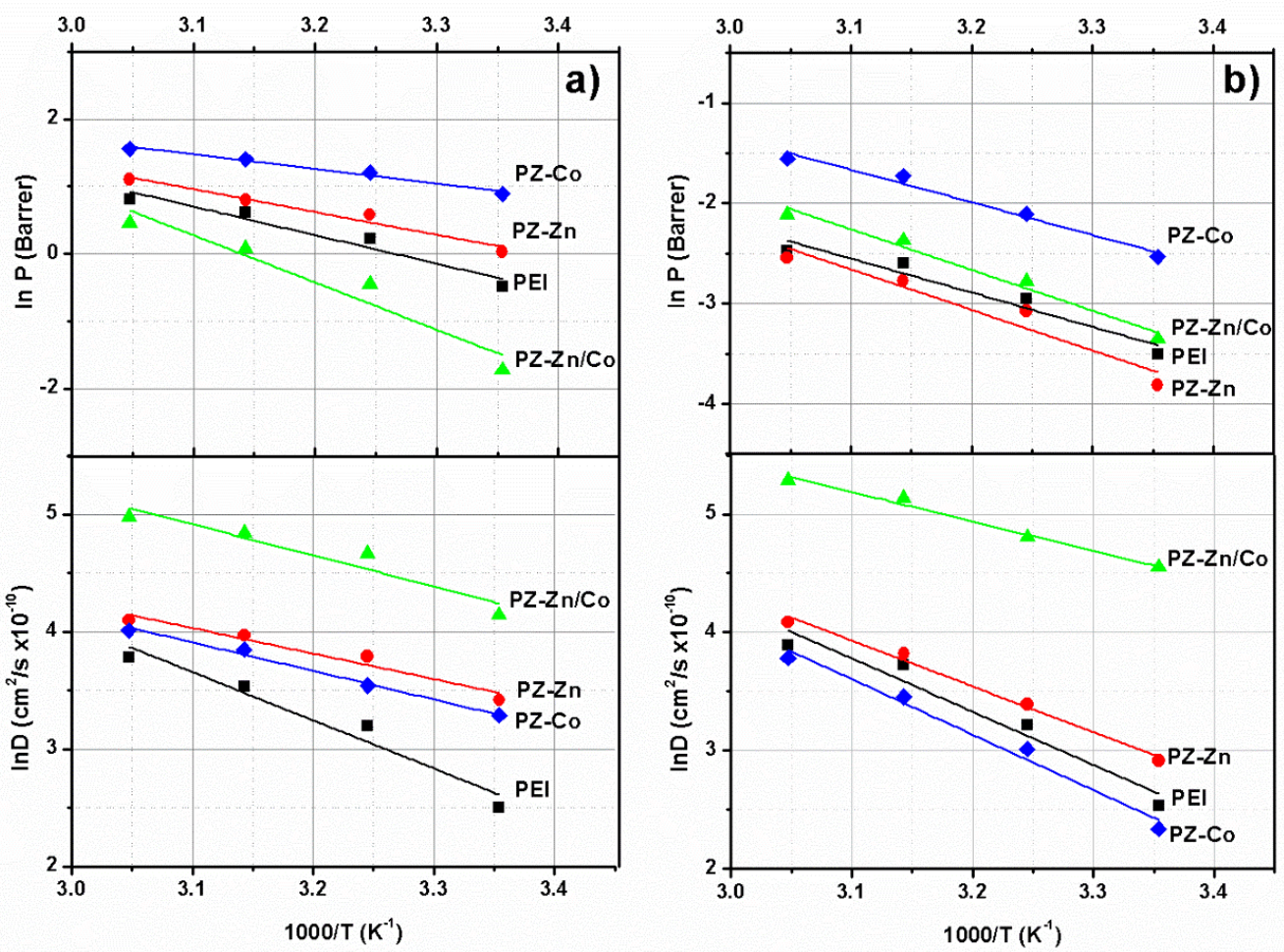

Figure 7. Arrhenius for apparent permeability and diffusion of a) $\mathrm{CO}_{2}$, b) $\mathrm{N}_{2}$, at 2 bars. Color symbol Black, Red, Green, and blue corresponding to PEI, PZ-Zn, PZ-Zn/Co and PZ-Co

Note that the enthalpy of sorption of $\mathrm{CO}_{2}$ in the $\mathrm{PZ}-\mathrm{Zn} / \mathrm{Co}$ membrane is greater than that of its analogues (PZ-Zn and PZ-Co), which supports the low selectivity obtained $\alpha_{P_{a}\left(\mathrm{CO}_{2}\right) / P_{a}\left(N_{2}\right)}$ due to the adsorption of $\mathrm{CO}_{2}$ within the membrane and the possible obstruction of gaseous molecules through the hybrid membrane.

Table 3

Activation energy $\left(\mathrm{E}_{\mathrm{a}}\right)$ of the permeation and diffusion processes and sorption enthalpy for $\mathrm{CO}_{2}$ and $\mathrm{N}_{2}$ in the diverse tested membranes at 2 bar.

\begin{tabular}{l|cc|cc|cc}
\hline \multirow{2}{*}{ Films } & \multicolumn{2}{|c|}{$E_{P} / \mathrm{kJ} \mathrm{mol}^{-1}$} & \multicolumn{2}{c|}{$E_{D} / \mathrm{kJ} \mathrm{mol}^{-1}$} & \multicolumn{2}{c}{$\Delta H_{s} / \mathrm{kJ} \mathrm{mol}^{-1}$} \\
\cline { 2 - 7 } & $\mathrm{CO}_{2}$ & $\mathrm{~N}_{2}$ & $\mathrm{CO}_{2}$ & $\mathrm{~N}_{2}$ & $\mathrm{CO}_{2}$ & $\mathrm{~N}_{2}$ \\
\hline PEI & $32.8 \pm 1.8$ & $31.0 \pm 0.3$ & $36.0 \pm 0.3$ & $37.4 \pm 0.3$ & $-3.2 \pm 2.1$ & $-6.4 \pm 0.6$ \\
PZ-Zn & $17.6 \pm 1.3$ & $36.9 \pm 0.3$ & $18.1 \pm 0.3$ & $30.5 \pm 0.3$ & $-0.6 \pm 1.6$ & $6.4 \pm 0.6$ \\
PZ-Zn/Co & $58.1 \pm 1.1$ & $33.8 \pm 0.4$ & $22.1 \pm 0.2$ & $20.7 \pm 0.2$ & $36.0 \pm 1.3$ & $13.0 \pm 0.6$ \\
PZ-Co & $18.0 \pm 0.8$ & $27.0 \pm 0.5$ & $20.2 \pm 0.3$ & $43.8 \pm 0.3$ & $-2.1 \pm 1.1$ & $-16.8 \pm 0.8$ \\
\hline
\end{tabular}




\subsection{Gas mixture study}

The estimation of permeability to single and mixture of gases at atmospheric pressure through PEI and PZIFs at $10 \%$ ZIF weight concentration was carried out by an isostatic method described in the experimental section. Figure 8 shows the apparent permeability values (of the individual gases $\mathrm{O}_{2}, \mathrm{CO}_{2}$, and $\mathrm{CH}_{4}$ ) and the permselectivity of the gas pairs. In Figure 8a, it can be observed that in all membranes, $\mathrm{CO}_{2}$ is the most permeable gas of the three tested, followed by $\mathrm{O}_{2}$ and $\mathrm{CH}_{4}$, as it could be expected from reported data in other polymers. The greater solubility of $\mathrm{CO}_{2}$ caused by its condensability is mainly responsible for the high $\mathrm{P}$ values. A comparison between membranes shows that PEI offers and intermediate barrier to all these three gases than PZ-Zn (higher) and PZ-Co (lower).
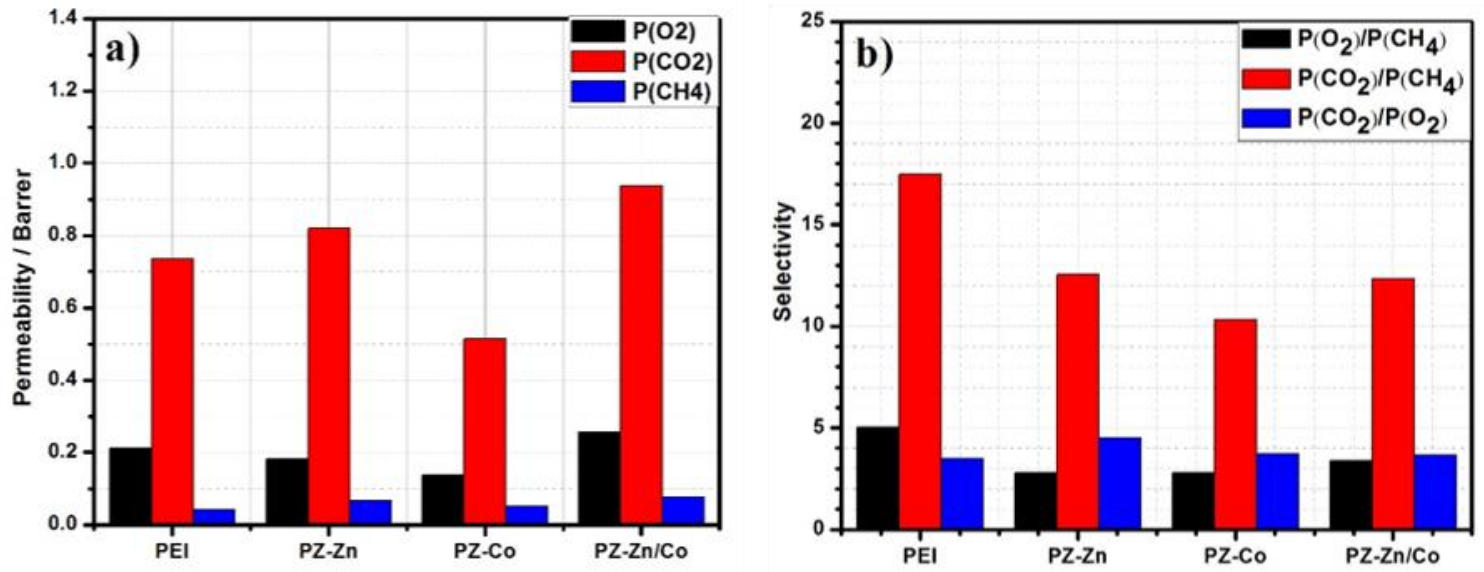

Figure 8. Values of the permeability coefficients of single gas in PEI and PZIFs membranes (plot a) and apparent selectivity (plot b) measured at room temperature and at 1 atm of pressure.

After these results, one could expect that the $\mathrm{P}_{\mathrm{a}}$ values for the PZ-Zn / Co membrane would be intermediate to those with the single metallic ZIFs (PZ-Zn and PZ-CO), however the permeability coefficients of $\mathrm{O}_{2}, \mathrm{CO}_{2}$ and $\mathrm{CH}_{4}$ in the $\mathrm{PZ}-\mathrm{Zn} / \mathrm{Co}$ are larger showing that the $\mathrm{Z}-\mathrm{Zn} / \mathrm{Co}$ filling is a solid solution and its behavior is typical of a new material with different properties than the Z-Zn and Z-Co.

From the values of apparent permeability (see Table 4) the permselectivity of the membranes for the diverse gas pairs were calculated and are also presented in Figure 8-b. In general, the results obtained for the PZIFs membranes showed low selectivities compared to the PEI as blank; however, it is important to mention that the selectivity behavior of the membrane series preserves a pattern similar to the selectivities shown in Figure 5-a. The relationship of 
the observed pattern (by the variable-volume pressure-constant method and isostatic method) allows us to suggest that the concentration in percent weight of the PZIFs membranes is a potential factor for the increase of selectivity of the gases in question.

Table 4

Permeability and selectivity of single gases at conditions of 1 atm and room temperature.

\begin{tabular}{|c|c|c|c|c|c|c|}
\hline \multirow{2}{*}{ Sample } & $\begin{array}{c}\mathrm{P}_{\mathrm{a}} \times 10^{-1} \\
\left(\mathrm{O}_{2}\right)\end{array}$ & $\begin{array}{c}P_{\mathrm{a}} \times 10^{-1} \\
\left(\mathrm{CO}_{2}\right) \\
\end{array}$ & $\begin{array}{c}\mathrm{P}_{\mathrm{a}} \times 10^{-2} \\
\left(\mathrm{CH}_{4}\right)\end{array}$ & \multirow[t]{2}{*}{$\mathrm{P}\left(\mathrm{O}_{2}\right) / \mathrm{P}\left(\mathrm{CH}_{4}\right)$} & \multirow[t]{2}{*}{$\mathrm{P}\left(\mathrm{CO}_{2}\right) / \mathrm{P}\left(\mathrm{CH}_{4}\right)$} & \multirow[t]{2}{*}{$\mathrm{P}\left(\mathrm{CO}_{2}\right) / \mathrm{P}\left(\mathrm{O}_{2}\right)$} \\
\hline & & Barrer & & & & \\
\hline PEI & $2.1 \pm 0.1$ & $7.4 \pm 0.4$ & $4.2 \pm 0.2$ & $5.0 \pm 0.5$ & $17.5 \pm 1.8$ & $3.5 \pm 0.4$ \\
\hline PZ-Zn & $1.8 \pm 0.1$ & $8.2 \pm 0.4$ & $6.6 \pm 0.3$ & $2.8 \pm 0.3$ & $12.5 \pm 1.2$ & $4.5 \pm 0.5$ \\
\hline PZ-Co & $1.4 \pm 0.1$ & $5.1 \pm 0.3$ & $5.0 \pm 0.2$ & $2.8 \pm 0.3$ & $10.4 \pm 1.0$ & $3.7 \pm 0.4$ \\
\hline PZ-Zn/Co & $2.6 \pm 0.1$ & $9.4 \pm 0.5$ & $7.6 \pm 0.4$ & $3.4 \pm 0.3$ & $12.3 \pm 1.3$ & $3.7 \pm 0.4$ \\
\hline
\end{tabular}

Figure 9 shows the gas permeability measured by the isostatic method with two gas mixtures, $\mathrm{CO}_{2} / \mathrm{CH}_{4}$ and $\mathrm{CH}_{4} / \mathrm{C}_{2} \mathrm{H}_{4}$.
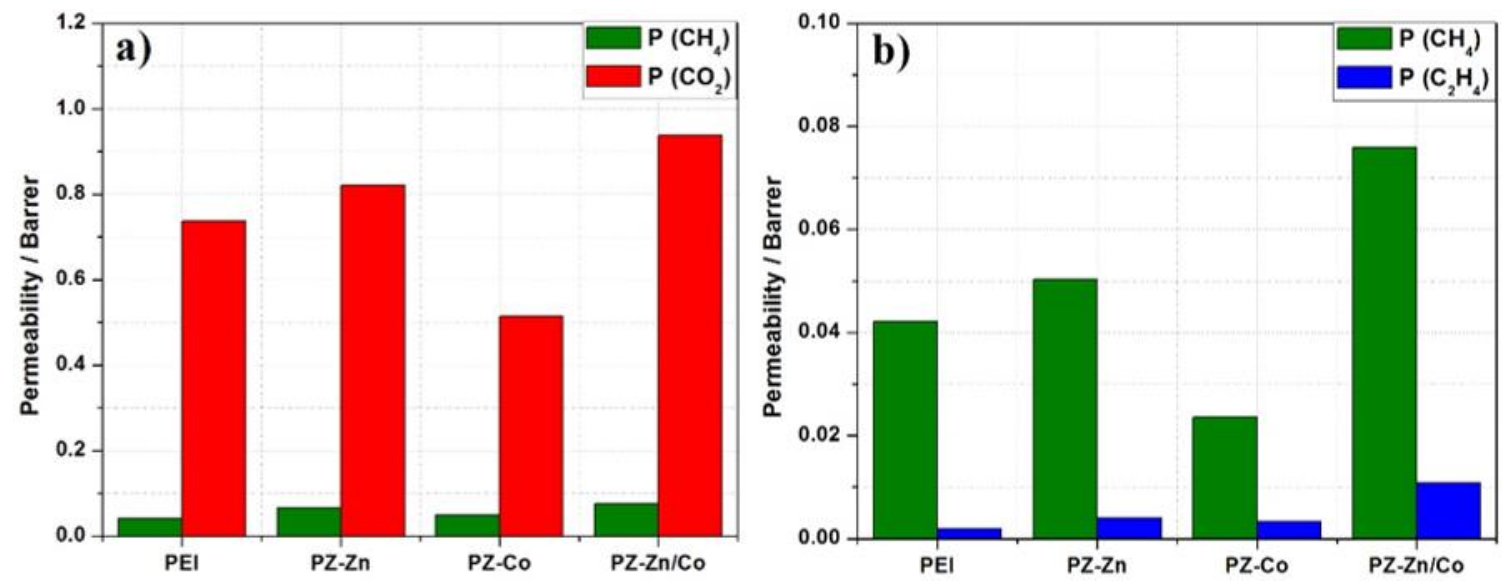

Figure 9. Graphics of a) permeation of mixture gases $\left(\mathrm{CO}_{2} / \mathrm{CH}_{4}\right)$ in membrane series and b) selectivity of mixture gases $\left(\mathrm{CH}_{4} / \mathrm{C}_{2} \mathrm{H}_{4}\right)$ in membrane series, both at room temperature and $1 \mathrm{~atm}$ of pressure.

Similar to the apparent permeation of single gases, the transport values of these gas mixtures through the PZIFs membranes were higher (with the exception of the PZ-Co membrane) than through PEI membrane. In the case of the $\mathrm{CO}_{2} / \mathrm{CH}_{4}$ mixture (see Figure 9-a) the permeation values obtained for $\mathrm{CO}_{2}$ are in the $5.13 \times 10^{-1}-9.37 \times 10^{-1}$ barrer range, while that for $\mathrm{CH}_{4}$, are in the $4.21 \times 10^{-2}$ to $7.59 \times 10^{-2}$ barrer range. The transport is slower for $\mathrm{CH}_{4}$ than for $\mathrm{CO}_{2}$, in agreement with reported literature values and suggests that the transport of gases through the PZIFs and PEI membranes is mainly due to the kinetic diameter of the species in question ( $0.38 \mathrm{~nm}$ for $\mathrm{CH}_{4}$ and $0.33 \mathrm{~nm}$ for $\mathrm{CO}_{2}$ ). This considerations is also valid for the $\mathrm{CH}_{4} / \mathrm{C}_{2} \mathrm{H}_{4}$ 
mixture. As can be observed in Figure 9-b the permeabilities of $\mathrm{CH}_{4}$ are greater than those of $\mathrm{C}_{2} \mathrm{H}_{4}$ (with kinetic diameters of 0.38 and 0.39, respectively). [20] Comparing between membranes, a similar profile to those observed for pure gases and mixtures were obtained. The PZ-Zn/Co membrane presented the greatest permeabilities followed by PZ-Zn, and PEI, and again the PZ-Co showed the greatest barrier properties.

Table 5. Permeability and selectivity values of mixture gases at $1 \mathrm{~atm}$ and room temperature.

\begin{tabular}{|c|c|c|c|c|c|c|}
\hline \multirow{3}{*}{ Sample } & \multicolumn{3}{|c|}{$\mathrm{CO}_{2} / \mathrm{CH}_{4}$} & \multicolumn{3}{|c|}{$\mathrm{CH}_{4} / \mathrm{C}_{2} \mathrm{H}_{4}$} \\
\hline & $\mathrm{Px} 10^{-2}\left(\mathrm{CH}_{4}\right)$ & $\overline{P x} 10^{-1}\left(\mathrm{CO}_{2}\right)$ & \multirow{2}{*}{$\alpha\left(\mathrm{CO}_{2} / \mathrm{CH}_{4}\right)$} & $\mathrm{Px} 10^{-2}\left(\mathrm{CH}_{4}\right)$ & $\mathrm{Px} 10^{-3}\left(\mathrm{C}_{2} \mathrm{H}_{4}\right)$ & \multirow{2}{*}{$\alpha\left(\mathrm{CH}_{4} / \mathrm{C}_{2} \mathrm{H}_{4}\right)$} \\
\hline & \multicolumn{2}{|c|}{ Barrer } & & \multicolumn{2}{|c|}{ Barrer } & \\
\hline PEI & $4.21 \pm 0.21$ & $7.36 \pm 0.37$ & $17.49 \pm 0.30$ & $4.21 \pm 0.21$ & $1.85 \pm 0.09$ & $22.73 \pm 0.15$ \\
\hline PZ-Zn & $6.55 \pm 0.30$ & $8.20 \pm 0.41$ & $12.53 \pm 0.40$ & $5.02 \pm 0.25$ & $4.04 \pm 0.20$ & $12.44 \pm 0.20$ \\
\hline PZ-Co & $4.97 \pm 0.25$ & $5.13 \pm 0.26$ & $10.34 \pm 0.40$ & $2.35 \pm 0.12$ & $3.36 \pm 0.17$ & $7.00 \pm 0.20$ \\
\hline PZ-Zn/Co & $7.59 \pm 0.38$ & $9.37 \pm 0.47$ & $12.34 \pm 0.42$ & $7.59 \pm 0.38$ & $1.09 \pm 0.05$ & $6.99 \pm 0.22$ \\
\hline
\end{tabular}

Table 5 presents the permeability of the mixtures and the permselectivities calculated from the $\mathrm{P}$ values. The selectivities determined for both gas mixtures $\left(\mathrm{CO}_{2} / \mathrm{CH}_{4}\right.$ and $\left.\mathrm{CH}_{4} / \mathrm{C}_{2} \mathrm{H}_{4}\right)$ in the series of membranes showed that the polymer base PEI presents a greater gas discrimination compared to the hybrid membranes with $10 \%$ ZIF weight concentration. Nevertheless, we suggest that the selectivity of PZIFs can change with ZIF concentration according to the results obtained with the variable-volume pressure-constant method.

\section{Conclusions}

The series of membranes obtained had regular thicknesses $(100 \pm 18 \mu \mathrm{m})$ and free of defects; They also exhibited good flexibility during the assembly process and did not present ruptures or breaking points during the permeation process.

In this work, single gas permeation values of $\mathrm{CO}_{2}$ and $\mathrm{N}_{2}$, through PEI membranes containing ZIFs at $10 \%$ and $20 \%$ weight were measured by the "time-lag" method. In addition, the permeation values of single gases $\left(\mathrm{O}_{2}, \mathrm{CO}_{2}\right.$ and $\left.\mathrm{CH}_{4}\right)$ and gas mixtures $\left(\mathrm{CO}_{2} / \mathrm{CH}_{4}\right.$ and $\mathrm{CH}_{4} /$ $\mathrm{C}_{2} \mathrm{H}_{4}$ ) through PZIFs membranes with $10 \%$ of $\mathrm{ZIF}$ were obtained by an "isostatic" procedure at atmospheric pressure. The PZIFs with fillers of Z-Zn and Z-Co showed apparent selectivities $\left(\alpha_{P_{a}\left(\mathrm{CO}_{2}\right) / P_{a}\left(N_{2}\right)}\right)$ of 39.6 and 27.5 respectively, higher than the $\alpha_{P_{a}\left(\mathrm{CO}_{2}\right) / P_{a}\left(N_{2}\right)}$ 
of the PEI membrane, while the membrane with the bimetallic ZIF (PZ-Zn/Co) showed the lowest $\alpha_{P_{a}\left(\mathrm{CO}_{2}\right) / P_{a}\left(N_{2}\right)}$ selectivity (10.3) of the membrane series (under conditions of $25{ }^{\circ} \mathrm{C}$ and 2 bar). It is proposed that the selectivity of the membrane series can be attributed to two critical factors: the particle size/distribution ratio in the polymer base and sorption of $\mathrm{CO}_{2}$ at local sites of the bimetallic mixture

The permeability values for the PZIFs vary with respect to the concentration of the filler and the adsorbate-adsorbent ratio. The results obtained in the PZ-Zn hybrid membrane with 10\% filler weight showed a slight increase in the $\alpha_{P_{a}\left(\mathrm{CO}_{2}\right) / P_{a}\left(N_{2}\right)}$ while that the PZ-Co and PZ$\mathrm{Zn} / \mathrm{Co}$ membranes with $10 \mathrm{wt} \%$ filler showed $\alpha_{P_{a}\left(\mathrm{CO}_{2}\right) / P_{a}\left(N_{2}\right)}$ lower than the PEI control membrane, The selectivity of $\mathrm{CO}_{2}$ in membranes of concentration $10 \%$ wt of ZIFs was lower than the PEI however, when doubling the concentration (20\% wt of ZIFs) the increase in selectivity was observed only for the PZ-Zn and PZ-Co membranes.

The activation energy calculated using Arrhenius expression in the activated state theory shows activation energies associated with $\mathrm{CO}_{2}$ permeation coefficients in the membranes were reducing in the order PZ-Zn/Co> PEI> PZ-Zn> PZ-Co, at 2 bars. However the activation energies for $\mathrm{N}_{2}$ showed less variation compared to $\mathrm{CO}_{2}$. The values of the apparent sorption enthalpies of $\mathrm{CO}_{2}$ and $\mathrm{N}_{2}$, presented by the PZIFs is of the same order as the fillings in its single phase. The reults indicate that heats solubility $\mathrm{CO}_{2}$ in PEI and hibrid membranes with fillers Z-Zn and Z-Co are exothermic processes. For filling the membrane with Z-Zn/Co heats of solubility of $\mathrm{CO}_{2}$ and $\mathrm{N}_{2}$ are endothermic processes.

\section{Acknowledgment}

This research has been supported by the ENE/2015-69203-R project, granted by the

Ministerio de Economía y Competitividad (MINECO), Spain; Also authors are grateful to UNAM-DGAPA-PAPIIT projects IG-100185, and IG-114818.

This study was partially supported by the CONACyT (Mexico) projects 2013-05-231461 and CB-2014-01-235840.

The authors appreciate the access to the experimental facility of the National Laboratory for Energy Conversion and Storage (CONACyT) to carry out the experimental study.

\section{References}


1 P. Bernardo, E. Drioli and G. Golemme. Membrane Gas Separation: A Review/State of the Art. Ind. Eng. Chem. Res., 48 (10) (2009), 4638. https://doi.org/10.1021/ie8019032.

2 W. Yave, M. G. Buonomenna and G. Golemme. Some approaches for high performance polymer based membranes for gas separation: block copolymers, carbon molecular sieves and mixed matrix membranes. RSC Advances, 2 (2012), 10745. https://doi.org/10.1039/C2RA20748F

3 A. W. Thornton, D. Dubbeldam, M. S. Liu, B. P. Ladewig, A. J. Hilla and M. R. Hill. Feasibility of zeolitic imidazolate framework membranes for clean energy applications. Energy \& Environmental Science, 5 (2012), 7637. https://doi.org/10.1039/C2EE21743K

4 Y. Zhang, J. Sunarso, S. Liu, R.Wang. Current status and development of membranes for CO2/CH4 separation: A review. International Journal of Greenhouse Gas Control, 12 (2013), 84. https://doi.org/10.1016/j.ijggc.2012.10.009

5 Y. Li, G. He, S. Wang, S. Yu , F. Pan , H. Wu and Z. Jiang. Recent advances in the fabrication of advanced composite membranes. Royal Society of chemistry, 1 (2013), 10058. https://doi.org/10.1039/C3TA01652H.

6 Troughton, M. J. Handbook of Plastics Joining: A Practical Guide. Elsevier Inc, 2008.

7 H. Farong, W. Xueqiu \& L. Shijin. The Thermal Stability of Polyetherimide. Polymer Degradation and Stability, 18 (1987), 247. https://doi.org/10.1016/01413910(87)90005-X.

8 V. Guerrero, H. Jeong and M. McCarthy. Synthesis of Zeolitic Imidazolate Framework Films and Membranes with Controlled Microstructures. Langmuir, 18, 26 (2010), 14636. https://doi.org/10.1021/la102409e.

9 N. Stock, S. Biswas. Synthesis of Metal-Organic Frameworks (MOFs): Routes to Various MOF Topologies, Morphologies, and Composites. American Chemical Society, 112 (2012), 93. https://doi.org/10.1021/cr200304e.

10 G. Liu, V. Chernikova, Y. Liu, K. Zhang, Y. Belmabkhout, O. Shekhah, C. Zhang, S. Yi, M. Eddaoudi and W. J. Koros. Mixed matrix formulations with MOF molecular sieving for key energy-intensive separations. Nature materials, 17 (2018), 283. https://doi.org/10.1038/s41563-017-0013-1.

11 S. Yu, S. Li, S. Huang, Z. Zeng, S. Cui, Y. Liu. Covalently bonded zeolitic imidazolate frameworks and polymers with enhanced compatibility in thin film nanocomposite membranes for gas separation. Journal of Membrane Science, 540 (017), 155. https://doi.org/10.1016/j.memsci.2017.06.047.

12 Keskin, E. Atci and S. Atomically detailed models for transport of gas mixtures in ZIF membranes and ZIF/polymer composite membranes. Industrial and Engineering Chemistry Research, 51, 7 (2012), 3091. https://doi.org/10.1021/ie202530f.

13 L. Xiang, L. Sheng, C. Wang, L. Zhang, Y. Pan and Y. Li. Amino-Functionalized ZIF7 Nanocrystals: Improved Intrinsic Separation Ability and Interfacial Compatibility in MixedMatrix Membranes for CO2/CH4 Separation. Advanced Materials, 29 (2017), 1606999. https://doi.org/10.1002/adma.201606999.

14 H. Wang, L. Zhao, W. Xu, S. Wang, Q. Ding, X. Lu, W, Guo. The properties of the bonding between $\mathrm{CO}$ and ZIF-8 structures: a density functional theory study. Theor Chem Acc, 134 (2015), 31. https://doi.org/10.1007/s00214-015-1636-4. 
15 H. Huang, W. Zhang, D. Liu, B. Liu, G. Chen and C. Zhong. Effect oftemperatureongasadsorptionandseparationinZIF-8:Acombined experimental and molecular simulation study. Chemical Engineering Science, 66 (2011), 6297. https://doi.org/10.1016/j.ces.2011.09.009.

16 K. Y. A. Lin, H. A. Chang. Ultra-High Adsorption Capacity of Zeolitic Imidazole Framework-67 (ZIF-67) for Removal of Malachite Green From Water. Chemosphere, 139 (2015), 624. https://doi.org/10.1016/j.chemosphere.2015.01.041.

17 R. Banerjee, A. Phan, B. Wang, C. Knobler, O. M. Yaghi. High-throughput synthesis of zeolitic imidazolate frameworks and application to CO2 capture. Science, 319 (2008), 939. https://doi.org/10.1126/science.1152516.

18 C. Sámano, R. Cabrera, J. Hernández, A. Lemus, E. Reguera. Separation of H2-CO2 and $\mathrm{CH} 4-\mathrm{CO} 2$ binary mixtures by zeolite-like imidazolate frameworks. Surfaces and Interfaces, 5 (2016), 55. https://doi.org/10.1016/j.surfin.2016.09.009.

19 Standard Test Method for Determining Gas Permeability Characteristics of Plastic Film and Sheeting. ASTM International (2009).

20 Y. Yampolskii, I. Pinnau and B. Freeman. Materials Science of Membranes for Gas and Vapor Separation. John Wiley \& Sons Ltd, 2006.

21 J. Villaluenga, B. Seoane and V. Compañ. Diffusional characteristics of coextruded linear low-density polyethylenes prepared from different conditions of processing. Journal of Applied Polymer Science, 70 (1998), 25. https://doi.org/10.1002/(SICI)1097-4628(19981003)70:1<23::AID-APP5>3.0.CO;2-W.

22 P. Cerisuelo, A. Alonso, S. Aucejo, R. Gavara and P. Hernandez. Modifications induced by the addition of a nanoclay in the functional and active properties of an EVOH film containing carvacrol for food packaging. Journal of Membrane Science, 423-424 (2012), 447. https://doi.org/10.1016/j.memsci.2012.08.021.

23 R. Gavara, R. Catala, P.M. Hernandez-Munoz, R.J. Hernandez. Evaluation of permeability through permeation experiments: isostatic and quasiisostatic methods compared. Packaging technology \& science, 9 (1996), 215. https://doi.org/10.1002/(SICI)1099-1522(199607)9:4<215::AID-PTS366>3.0.CO;2-U

24 ASTM D3985 - 05, Standard Test Method for Oxygen Gas Transmission Rate Through Plastic Film and Sheeting Using a Coulometric Sensor. ASTM International, West Conshohocken, PA. (2010).

25 Ma. Josephine, C. Ordoñez, K. J. Balkus Jr., J. P. Ferraris, I. H. Musselman. Molecular sieving realized with ZIF-8/Matrimid ${ }^{\circledR}$ mixed-matrix membranes. Journal of Membrane Science 361, 361 (2010), 28. https://doi.org/10.1016/j.memsci.2010.06.017.

26 C. Samano, J. Hernádez, R. Cabrera, J.A.I. Díaz and E. Reguera. Tuning the adsorption potential. Separation of aromatic hydrocarbons by cobalt and zinc zeolitic imidazolate frameworks. Colloids and Surfaces A: Physicochemical and Engineering Aspects, 506 (2016), 50. https://doi.org/10.1016/j.colsurfa.2016.06.008.

27 Cubllity, B. D. Elements of X-ray difraction. ADDISON-WESLEY PUBLISHING COMPANY, INC., 1956.

28 Y. Dai, J.R. Johnson, O. Karvan, D. S. Sholl, W.J. Koros. Ultem®/ZIF-8 mixed matrix hollow fiber membranes for CO2/N2 separations. Journal of Membrane Science , 401401 (2012), 76. https://doi.org/10.1016/j.memsci.2012.01.044. 
29 L. Hertäg, H. Bux, J. Caro, C. Chmelik, T. Remsungnen, M. Knauth and S. Fritzsche. Diffusion of CH4 and H2 in ZIF-8. Journal of Membrane Science, 377 (2011), 36. https://doi.org/10.1016/j.memsci.2011.01.019

30 C. Chmelik, J. van Baten and R. Krishna. Hindering effects in diffusion of $\mathrm{CO} 2 / \mathrm{CH} 4$ mixtures in ZIF-8 crystals. Journal of Membrane Science, 397-398 (2012), 87. https://doi.org/10.1016/j.memsci.2012.01.013

31 J. Li, J. Sculley, and H. Zhou. Metal-Organic Frameworks for Separations. American Chemical Society, 112 (2012), 869. https://doi.org/10.1021/cr200190s

32 Yang, R. Adsorbents: Fundamentals and applications. Wiley-Interscience, 2003.

33 H. Lin, L. Pei and C. T. Shung. PIM-1 as an organic filler to enhance the gas separation performance of Ultem polyetherimide. Journal ofMembrane Science, 453 (2014), 614. https://doi.org/10.1016/j.memsci.2013.11.045.

34 V. Compañ, L. F. Del Castillo, S.I. Hernández, M. López and E. Riande. On the crystallinity effect on the gas sorption in semicrystalline linear low density polyethylene (LLDPE). Journal of Polymer Science. Part B: Polymer Physics, 45 (2007), 1798. https://doi.org/10.1002/polb.21228. 